\title{
Một số yếu tố tác động đến quyết định chọn mua mặt hàng trang trí nội thất phòng khách của khách hàng tại Thành phố Hồ Chí Minh
}

\section{Factors affecting consumer's purchase decision on interior decoration for living room in Ho Chi Minh City}

\author{
Trần Thị Hương ${ }^{1 *}$ \\ ${ }^{1}$ Trường Cao Đẳng GTVT Trung Ương VI, Việt Nam \\ *Tác giả liên hệ, Email: huong120470@gmail.com
}

\begin{tabular}{|c|c|}
\hline THÔNG TIN & TÓM TẮT \\
\hline $\begin{array}{l}\text { OI: } 10.46223 / \mathrm{HCMCOUJS} \\
\text { con.vi.16.2.982.2021 }\end{array}$ & $\begin{array}{l}\text { Nghiên cứu này xem xét ảnh hưởng của các yếu tố tác động } \\
\text { đến quyết định chọn mua mặt hàng trang trí nội thất phòng } \\
\text { khách của khách hàng tại Thành phố Hồ Chí Minh (TP. HCM). } \\
\text { Mô hình nghiên cứu được kiểm định với } 275 \text { khách hàng mua } \\
\text { mặt hàng trang trí nội thất phòng khách tại địa bàn TP. HCM. }\end{array}$ \\
\hline Ngày nhận: 21/09/2020 & Phương pháp phân tích Cronbach's Alpha, phân tích EFA và \\
\hline Ngày nhận lại: 08/11/2020 & hồi quy được dùng để xác định các yếu tố tác động chính đến \\
\hline Duyệt đăng: 20/11/2020 & $\begin{array}{l}\text { quyết đị̂nh mua mặt hàng trang trí nội thất. Kết quả kiểm định } \\
\text { cho thây ba yếu tố chính tác động đến quyết định mua hàng } \\
\text { trang trí nội thất phòng khách là: (1) Sự cần thiết trang trí nội } \\
\text { thất phòng khách; (2) Yếu tố giá cả và (3) Yếu tố chất liệu của } \\
\text { mặt hàng trang trí nội thất phòng khách. Cuối cùng nghiên cứu } \\
\text { đã đưa ra những khuyến nghị cho các doanh nghiệp, đơn vị kinh } \\
\text { doanh mặt hàng trang trí nội thất. }\end{array}$ \\
\hline $\begin{array}{l}\text { yêu tô; trang trí nội thât; nội thât } \\
\text { phòng khách; chọn mua; quyết }\end{array}$ & AI \\
\hline định mua & $\begin{array}{l}\text { The research examines factors affecting decisions to buy } \\
\text { interior decoration in HCMC. These factors are tested by } 275 \\
\text { customers to buy interior decoration in HCMC. The study uses a } \\
\text { combination of Cronbach's Alpha, EFA, and Recurrent for } \\
\text { defining main factors affecting decisions to buy interior }\end{array}$ \\
\hline & decoration. The results reveal two factors affecting such as: (1) \\
\hline $\begin{array}{l}\text { Factor; interior decoration; } \\
\text { interior decoration in living } \\
\text { room; purchase decision }\end{array}$ & $\begin{array}{l}\text { Necessaries of interior decoration in the living room; (2) Price; } \\
\text { and (3) Material of interior decoration in the living room. The } \\
\text { research also suggests some recommendations for real interior } \\
\text { decoration companies. }\end{array}$ \\
\hline
\end{tabular}

\section{Giới thiệu}

TP. HCM là một trong những thành phố đông dân nhất cả nước, tăng trung bình gần 183 ngàn người/năm (Nhat Minh, 2020). Theo tờ trình của Sở Xây dựng TP. HCM, năm 2019 TP. HCM có khoảng 1.92 triệu căn nhà, căn hộ chung cư. Mật độ nhà ở trung bình là 913 căn $/ \mathrm{km}^{2}$. Dự báo năm 2030, TP cần xây thêm 830,000 căn nhà với 150 triệu $\mathrm{m}^{2}$ sàn nhà ở $(\mathrm{Le}, 2020)$. TP. HCM là nơi có mức sống cao ở Việt Nam. Với mức lương trung bình của người lao động là 456 USD/tháng (khoảng 10.3 triệu đồng/tháng), TP. HCM có mức lương dẫn đầu toàn quốc, cao hơn 
38\% so với mức bình quân cả nước (Thu Hang, 2018).

Cùng với các chi tiêu cho cuộc sống, người dân thành phố cũng rất quan tâm đến không gian sống trong căn nhà của họ. Căn nhà là nơi để ở và phục vụ các nhu cầu sinh hoạt của hộ gia đình, cá nhân; là nơi để thư giãn lấy lại sức sau những lúc làm việc mệt nhọc và là nơi để gia đình quay quần đầm ấm bên nhau. Theo nghiên cứu sơ bộ, có hai xu hướng rõ rệt mà các hộ gia đình chăm chút cho không gian sống của họ: (1) là trang trí hàng nội thất theo kiểu đơn giản thông thường được làm từ các doanh nghiệp địa phương; (2) là trang trí nội thất với các sản phẩm cao cấp được làm từ các doanh nghiệp lớn hay hàng nhập khẩu từ các nước tiên tiến.

Với số dân tăng và lượng nhà ở cũng tăng nhanh thì nhu cầu về mặt hàng trang trí nội thất ở TP. HCM là một con số lớn. Mục tiêu của nghiên cứu này nhằm xác định và kiểm định mô hình một số yếu tố tác động đến quyết định chọn mua mặt hàng trang trí nội thất của các hộ gia đình tại TP.HCM. Từ kết quả nghiên cứu, tác giả đề xuất các hàm ý quản trị cho các đơn vị sản xuất kinh doanh mặt hàng trang trí nội thất.

\section{Co' sở lý thuyết và mô hình nghiên cứu}

\subsection{Các yếu tố ảnh hưởng đến quyết định chọn mua sản phẩm của khách hàng}

Theo Kotler và Keller (2012), việc mua sắm của người tiêu dùng chịu ảnh hưởng của nhiều yếu tố khác nhau, trong đó phải kể đến bốn nhóm yếu tố chính là: văn hóa, xã hội, cá nhân và tâm lý.

- Nền văn hóa: Là yếu tố quyết định cơ bản nhất những mong muốn và hành vi của một người. Những người sống trong môi trường văn hóa khác nhau sẽ có hàng vi tiêu dùng khác nhau. Ngoài ra, hành vi mua sắm còn phụ thuộc vào nhánh văn hóa, nhánh văn hóa là bộ phận cấu thành nhỏ hơn của nền văn hóa có thể chia theo địa lý, dân tộc, tôn giáo. Các nhánh văn hóa khác nhau có lối sống riêng, phong cách tiêu dùng riêng;

- Các yếu tố xã hội: Hành vi mua sắm của người tiêu dùng cũng ảnh hưởng bởi những yếu tố xã hội như các nhóm tham khảo, gia đình và vai trò của vị trí xã hội;

- Các yếu tố cá nhân: Những quyết định mua sắm của người tiêu dùng cũng chịu ảnh hưởng bởi những đặc điểm cá nhân như: giới tính, tuổi tác và giai đoạn của chu kỳ sống, nghề nghiệp và thu nhập, lối sống;

- Nhóm yếu tố tâm lý: Việc lựa chọn mua sắm của một người còn chịu ảnh hưởng của bốn yếu tố tâm lý là động cơ, nhận thức, sự hiểu biết, niềm tin.

Theo Engel-Kollat-Blackwell (1968) và Howard và Sheth (1969 as cited in Jeff, n.d.), việc mua sắm của người tiêu dùng chịu tác động bởi nhóm yếu tố môi trường như chất lượng, giá cả, gia đình và nhóm yếu tố cá nhân như động cơ, tài chính, kiến thức, thái độ, cá tính, lối sống.

Mô hình thuyết hành động hợp lý (TRA) do Fishbein và Ajzen xây dựng năm 1975. Lý thuyết này cho rằng ý định hành vi được quyết định bởi thái độ cá nhân đối với hành vi, cùng sự ảnh hưởng của chuẩn chủ quan xung quanh việc thực hiện các hành vi đó. Trong đó, thái độ và chuẩn chủ quan có tầm quan trọng trong ý định hành vi.

Theo Solomon, Bamossy, Akegaard, và Hogg (2006), cho rằng quyết định mua sắm của người tiêu dùng thường được dựa trên sự đánh giá về chất lượng của sản phẩm hay thương hiệu của nó. Trước khi quyết định mua một sản phẩm nào thì người tiêu dùng thường có mức độ đắn đo lo lắng nhiều hay ít tỷ lệ thuận với giá trị của sản phẩm. Để giảm thiểu rủi ro, họ thường tham khảo trên internet hay hỏi thăm tin tức của sản phẩm từ bạn bè, người thân. 
Nghiên cứu của Huynh (2013) về các yếu tố ảnh hưởng đến quyết định mua xe tay ga hãng Honda của người tiêu dùng tại TP. HCM đã đề xuất mô hình gồm 05 yếu tố ảnh hưởng: (1) Giá trị nhân sự; (2) Giá trị chất lượng; (3) Giá trị tính theo giá; (4) giá trị cảm xúc; (5) giá trị xã hội.

Nghiên cứu của Do (2017) về các các yếu tố tác động đến quyết định mua ô tô tại Việt Nam. Tác giả đã đề xuất mô hình nghiên cứu gồm 06 yếu tố tác động đến quyết định mua ô tô tại Việt Nam: (1) Nhận thức về sự hữu ích; (2) Nhận thức kiểm soát hành vi - tài chính; (3) Cảm nhận về giá cả - chi phí; (4) Cảm nhận về an toàn - chất lượng; (5) Nhận thức rủi ro; và (6) Chuẩn chủ quan.

Hay theo luận văn Thạc sĩ của Vo (2013) nghiên cứu về các yếu tố ảnh hưởng đến quyết định mua nhà của khách hàng tại TP.HCM có 07 yếu tố gồm: (1) Tình hình tài chính; (2) Đặc điểm nhà; (3) Không gian sống; (4) Vị trí nhà; (5) Tiện nghi công cộng; (6) Môi trường sống; (7) Bằng chứng thực tế.

Nghiên cứu của T. Q. Nguyen (2014) về "Một số yếu tố tác động đến quyết định chọn mua căn hộ chung cư cao cấp của khách hàng tại Thành phố Hồ Chí Minh" cho rằng việc quyết định chọn mua căn hộ chung cư cao cấp của người dân TP. HCM ảnh hưởng bởi các yếu tố: (1) Các yếu tố văn hóa xã hội; (2) Yếu tố thuộc tính sản phẩm; (3) Yếu tố ảnh hưởng; (4) Thuế và thủ tục giấy tờ sở hữu căn hộ.

Ngoài ra, có hai nghiên cứu liên quan đến quyết định mua vật dụng cho ngôi nhà như nghiên cứu về các yếu tố ảnh hưởng đến quyết định mua Vật liệu nhẹ - Thạch cao của Pham (2009) nêu ra 08 yếu tố ảnh hưởng đến việc quyết định mua vật liệu nhẹ - thạch cao gồm: (1) Uy tín trong kinh doanh, (2) Giá cả sản phẩm, (3) Dịch vụ khách hàng, (4) Cửa hàng liên hệ mua sản phẩm, (5) Chất lượng và đặc tính của sản phẩm, (6) Ích lợi của sản phẩm, (7) Hoạt động giao nhận, (8) Thương hiệu sản phẩm. Nghiên cứu của V. V. Nguyen (2016) về các yếu tố giá trị thương hiệu ảnh hưởng đến ý định chọn mua nệm Kim Đan của người tiêu dùng TP. HCM gồm 06 yếu tố: (1) Nhận biết thương hiệu; (2) Liên tưởng thương hiệu; (3) Chất lượng cảm nhận; (4) Lòng trung thành thương hiệu; (5) Giá cả cảm nhận.

Đối với mặt hàng trang trí nội thất để trang trí cho căn nhà, việc mua sắm thường là sự đồng ý của cả hai vợ chồng. Hay trang trí phòng khách thường là quyết định của người chồng, còn trang trí phòng ngủ và nhà bếp thì nghiêng về quyết định của người vợ. Nhưng việc trang trí trong ngôi nhà có tính đồng nhất giữa các phòng, giữa các không gian với nhau nên cần sự đồng ý của cả hai người. Khi mua sắm hàng nội thất, thường người tiêu dùng quan tâm đến thuộc tính của sản phẩm. Các thuộc tính của sản phẩm bao gồm: Chức năng của sản phẩm, giá thành và chất lượng của sản phẩm (Kaplan \& Norton, 1996). Đối với sản phẩm là mặt hàng trang trí nội thất thì thuộc tính sản phẩm là chất lượng, kiểu dáng, chất liệu, màu sắc và giá cả sản phẩm.

Tác giả chưa thấy nghiên cứu nào thực hiện về các yếu tố tác động đến quyết định mua mặt hàng trang trí nội thất của người tiêu dùng (các hộ gia đình) tại TP.HCM. Trong khi đó nhu cầu và thực tế mua sắm mặt hàng này rất cao. Nên cần thiết có nghiên cứu liên quan đến việc xem xét các yếu tố ảnh hưởng đến quyết định mua mặt hàng trang trí nội thất.

Căn cứ vào những yếu tố ảnh hưởng đến quyết định mua của người tiêu dùng qua các lý thuyết, mô hình, nghiên cứu kể trên. Sau khi quan sát, tham khảo ý kiến của một số khách hàng và những người bán hàng nội thất, tác giả đưa ra các yếu tố cụ thể ảnh hưởng đến quyết định mua hàng trang trí nội thất của các chủ hộ ở địa bàn TP. HCM như sau: (1) sự cần thiết của đồ nội thất, (2) giá cả đồ nội thất, (3) chất liệu đồ nội thất, (4) kiểu dáng đồ nội thất, (5) màu sắc đồ nội thất. 


\subsection{Mặt hàng trang trí nội thất}

Đồ nội thất hay vật dụng, thiết bị nội thất là những loại tài sản (thường là động sản) và các vật dụng khác được bố trí, trang trí bên trong một không gian nội thất như căn nhà, căn phòng hay cả tòa nhà nhằm mục đích hỗ trợ cho các hoạt động khác nhau của con người trong công việc, học tập, sinh hoạt, nghỉ ngơi, giải trí như ghế, bàn, giường, tủ,...

Với mỗi ngôi nhà, phòng khách là căn phòng quan trọng. Khi mọi tinh hoa trang trí ở đây đều được gia chủ chăm chút kỹ lưỡng. Vì thế có thể nói phòng khách là bộ mặt của gia chủ. Phòng khách là nơi tiếp đón khách, bạn bè thân hữu và cũng là nơi nghỉ ngơi, sum họp của các thành viên trong gia đình. Khi lựa chọn các món đồ trang trí cho phòng khách, gia chủ thường căn cứ vào tính thẩm mỹ, sự sang trọng, tính hợp phong thủy hay sự yêu thích của bản thân và gia đình. Các đồ dùng trang trí nội thất trong phòng khách thường là:

- Bàn, ghế uống nước, ghế sofa: Vật liệu của bàn ghế uống nước, ghế sofa có thể là gỗ, bộc nệm, thủy tinh, mây tre lá...Đây là món đồ nội thất quan trọng bậc nhất trong phòng khách. Chúng giúp không gian phòng khách đẹp, sang trọng và để sử dụng đón tiếp khách và có thể là nơi nghỉ ngơi thư giãn cho các thành viên trong gia đình;

- Bàn trà: Đi kèm theo bộ ghế sofa là bàn trà với các kiểu dáng đa dạng. Dù phòng khách nhỏ hay lớn, chật hay rộng bộ ghế sofa và bàn trà cũng đi kèm với nhau. Bàn trà sofa có nhiều chất liệu khác nhau như bàn trà mặt đá, bàn trà mặt kính hay bàn trà mặt gỗ;

- Kệ tivi: Món đồ nội thất đa số các hộ gia đình có trang bị là kệ tivi. Chúng không những đơn thuần là giá mà chúng còn được sử dụng như món đồ trang trí. Do đó, kệ tivi cũng được các gia chủ lựa chọn kỹ;

- Kệ trang trí, vách ngăn: Kệ trang trí, vách ngăn giúp phòng khách đẹp hơn khi bài trí nhiều món đồ khác nhau. Nếu phòng khách có nhiều không gian thì kệ trang trí có thể đi kèm với vách ngăn và tủ rượu.

Bên cạnh phòng khách, phòng ngủ và nhà ăn cũng không kém phần quan trọng và được chủ căn hộ chăm chút trang trí nội thất phù hợp.

Đồ trang trí phòng ngủ gồm: giường ngủ, tủ quần áo, bàn trang điểm, kệ tivi, rèm.

Đồ trang trí phòng bếp gồm: bộ bàn ăn, tủ bếp.

Ngoài ra, chủ căn nhà có thể trang trí thêm cho căn nhà những đồ vật mà mình ưa thích.

\section{Mô hình nghiên cứu và phương pháp nghiên cứu}

\subsection{Mô hình nghiên cúu}

Mô hình nghiên cứu một số yếu tố tác động đến quyết định mua mặt hàng trang trí nội thất, chủ yếu nghiên cứu về đồ nội thất trang trí phòng khách của ngôi nhà và các giả thuyết được trình bày ở Hình 1, gồm: (1) Sự cần thiết trang trí nội thất phòng khách; (2) Yếu tố giá cả của đồ nội thất; (3) Yếu tố chất liệu của đồ nội thất; (4) Yếu tố kiểu dáng của đồ nội thất; (5) Yếu tố màu sắc của đồ nội thất.

Các giả thuyết đặt ra:

Giả thuyết H1: Sụ cần thiết trang trí phòng khách có tác động đồng biến với quyết định chọn mua đồ nội thất

Giả thuyết H2: Yếu tố giá cả của đồ nội thất có tác động đồng biến với quyết định chọn mua đồ nội thất 
Giả thuyết H3: Yếu tố chất liệu của đồ nội thất tác động đồng biến với quyết định chọn mua đồ nọi thất

Giả thuyết H4: Yếu tố kiểu dáng của đồ nội thất tác động đồng biến với quyết định chọn mua đồ nội thất

Giả thuyết H5: Yếu tố màu sắc của đồ nội thất tác động đồng biến với quyết định chọn mua đồ nọi thất

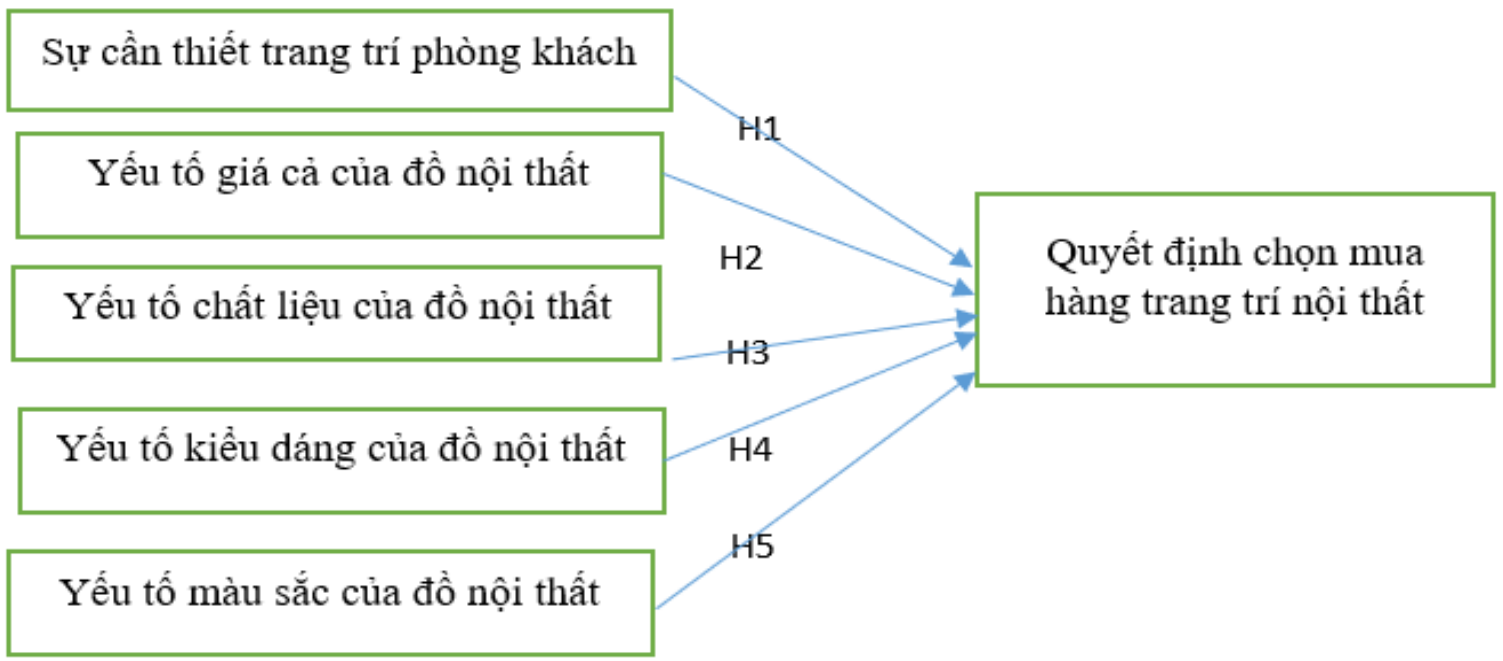

Hình 1. Mô hình nghiên cứu đề xuất

Trên cơ sở nghiên cứu và quan sát, tác giả đã phỏng vấn với 10 chuyên gia (gồm 06 khách hàng đã mua hàng nội thất, 04 người kinh doanh hàng nội thất) để xác định lại câu chữ trong bảng câu hỏi. Nghiên cứu đã xây dựng các biến số tiềm ẩn (latent variable), biến số quan sát (observed variable) làm cơ sở cho việc hình thành bảng câu hỏi và thiết kế mô hình nghiên cứu.

\section{Bảng 1}

Các khái niệm, thang đo và ký hiệu sử dụng trong mô hình nghiên cứu

\begin{tabular}{|l|c|c|}
\hline \multicolumn{1}{|c|}{ Biến số } & Thang đo & Các ký hiệu \\
\hline Sự cần thiết trang trí nội thất & Liker 5 điểm & CTHIET \\
\hline Yếu tố giá cả & Liker 5 điểm & GIACA \\
\hline Yếu tố chất liệu & Liker 5 điểm & CHATLIEU \\
\hline Yếu tố kiểu dáng & Liker 5 điểm & KIEUDANG \\
\hline Yếu tố màu sắc & Liker 5 điểm & MAUSAC \\
\hline Yếu tố khác & Liker 5 điểm & KHAC \\
\hline Tuổi & Tỷ lệ & TUOI \\
\hline Mức thu nhập & Tỷ lệ & THUNHAP \\
\hline Công việc hiện tại & Tỷ lệ & CONGVIEC \\
\hline Thời gian mua sắm & Khoảng cách & THOIGIAN \\
\hline Thông tin về mặt hàng TTNT & Tỷ lệ & TTIN \\
\hline Nơi thường mua mặt hàng TTNT & Tỷ lệ & TMUANT \\
\hline
\end{tabular}

Nguồn: Kết quả từ phần mềm SPSS26 của tác giả 
Thang đo sự cần thiết trang trí nội thất được đo lường bằng năm biến quan sát, với nội dung: (1) Cần trang trí phòng khách cho ngôi nhà thật đẹp; (2) Trang trí phòng khách theo phong cách sang trọng; (3) Trang trí phòng khách theo kiểu ấm cúng; (4) Trang trí phòng khách theo sự đơn giản, tiện dụng; (5) Trang trí phòng khách theo đồ nội thất thông minh. Thang đo yếu tố giá cả của đồ trang trí nội thất phòng khách được đo lường bằng năm biến quan sát với nội dung: (1) Chọn mặt hàng cao cấp; (2) Chọn mặt hàng trung bình; (3) Chọn mặt hàng có thương hiệu tốt; (4) Chọn mặt hàng nhập khẩu; (5) Không quan trọng giá cả miễn là thích. Yếu tố chất liệu của đồ trang trí nội thất được đo lường bằng năm biến quan sát với nội dung: (1) Gỗ là chất liệu quan tâm nhất; (2) Chọn chất liệu thủy tinh; (3) Chọn chất liệu vải nhung, nhựa; (4) Chọn chất liệu hàng mây tre lá; (5) Chọn chất liệu gạch, đá đẹp. Thang đo yếu tố kiểu dáng của đồ trang trí nội thất phòng khách được đo lường bằng năm biến quan sát với nội dung: (1) Thích chọn kiểu dáng cầu kỳ tỉ mĩ; (2) Thích chọn kiểu dáng Châu Âu, sang trọng; (3) Thích chọn kiểu cổ điển; (4) Thích chọn kiểu hài hòa; (5) Thích chọn kiểu mộc mạc đơn giản. Thang đo yếu tố màu sắc của đồ trang trí nội thất phòng khách được đo lường bằng năm biến quan sát với nội dung: (1) Thích chọn màu sắc tươi sáng; (2) Thích chọn màu tối mạnh mẽ; (3) Thích chọn màu cá tính, lạ mắt; (4) Thích chọn màu ấm cúng tạo không gian hạnh phúc; (5) Thích màu của thiên nhiên thư giãn, yên tĩnh.

Nghiên cứu này được sử dụng kỹ thuật phỏng vấn trực tiếp bằng bảng câu hỏi chi tiết với các cư dân sống tại $\mathrm{TP}$. HCM (chọn ngẫu nhiên những người đã từng mua sắm mặt hàng trang trí nội thất phòng khách). Thời gian thực hiện điều tra khảo sát từ tháng 05/2020 đến 06/2020. Kích thước mẫu là $n=300$ phiếu, thu về 287 phiếu. Mẫu chính thức sử dụng được là 275 phiếu, loại 12 phiếu không hợp lệ. Người tham gia trả lời bảng câu hỏi với tỉ lệ nam giới là 113 người (chiếm $41 \%$ ) và nữ giới là 162 người (chiếm 59\%) có độ tuổi từ 25 tuổi trở lên; với 112 người tuổi từ $25-30$ (chiếm 40\%), 93 người tuổi từ $31-40$ (chiếm 34\%) và 71 người tuổi từ 41 trở lên (chiếm 26\%). Về thành phần, có 93 người là nhân viên (chiếm 35\%); 67 người là tự kinh doanh (chiếm 24\%); 21 người là chuyên viên (chiếm 7\%) và 94 người là công việc khác (chiếm 34\%).

Theo Hair, Black, Babin, và Anderson (2014), tỷ lệ quan sát/biến đo lường tối thiểu là $5: 1$. Nghiên cứu có 30 biến đo lường nên số mẫu dự kiến là 5 x $30=150$. Thực tế, tổng số lượng mẫu hợp lệ thu thập được là 275. Bảng câu hỏi sử dụng thang đo dạng Likert 5 điểm được sử dụng từ 1 (hoàn toàn không đồng ý) đến 5 (hoàn toàn đồng ý) (Bảng 1). Dữ liệu thu thập được tiến hành sàng lọc và xử lý dữ liệu bằng phần mềm SPSS thông qua các phân tích giá trị trung bình, phân tích Cronbach's Alpha, nhân tố khám phá (EFA), tương quan và hồi quy đa biến. Theo T. D. Nguyen (2013), Cronbach's Alpha là hệ số được nhiều nghiên cứu ứng dụng nhất trong việc đánh giá độ tin cậy của những thang đo đa biến, bởi vì nó có thể được dùng để đánh giá tính nhất quán của các biến quan sát trong cùng một thang đo để đo lường một khái niệm.

\section{Phân tích dữ liệu và phương pháp nghiên cứu}

\subsection{Phân tích giá trị trung bình}

\section{Bảng 2}

Kết quả khảo sát thực trạng mua mặt hàng trang trí nội thất tại TP. HCM

\begin{tabular}{|l|l|c|c|}
\hline \multirow{2}{*}{ Biến quan sát } & \multicolumn{1}{|c|}{ Diễn giải } & $\begin{array}{c}\text { Giá trị } \\
\text { trung bình }\end{array}$ & $\begin{array}{c}\text { Độ lệch } \\
\text { chuẩn }\end{array}$ \\
\hline CTHIET1 & Cần trang trí phòng khách cho ngôi nhà thật đẹp & 4.78 & 0.638 \\
\hline CTHIET2 & Trang trí phòng khách theo phong cách sang trọng & 4.56 & 0.924 \\
\hline
\end{tabular}




\begin{tabular}{|c|c|c|c|}
\hline Biến quan sát & Diễn giải & $\begin{array}{l}\text { Giá trị } \\
\text { trung bình }\end{array}$ & $\begin{array}{l}\text { Độ lệch } \\
\text { chuẩn }\end{array}$ \\
\hline CTHIET3 & Trang trí phòng khách theo kiểu ấm cúng & 4.65 & 0.820 \\
\hline CTHIET4 & Trang trí phòng khách theo sự đơn giản, tiện dụng & 4.61 & 0.853 \\
\hline CTHIET5 & Trang trí phòng khách theo đồ nội thất thông minh & 4.00 & 0.667 \\
\hline GIACA & Chọn mặt hàng cao cấp & 4.13 & 0.936 \\
\hline GIACA2 & Chọn mặt hàng trung bình & 4.16 & 1.033 \\
\hline GIACA3 & Chọn mặt hàng có thương hiệu tốt & 4.75 & 0.715 \\
\hline GIACA4 & Chọn mặt hàng nhập khẩu & 4.16 & 0.817 \\
\hline GIACA5 & Không quan trọng giá cả miễn là thích & 4.06 & 0.946 \\
\hline CHATLIEU1 & Gỗ là chất liệu quan tâm nhất & 4.62 & 0.910 \\
\hline CHATLIEU2 & Chọn chất liệu thủy tinh & 3.67 & 0.942 \\
\hline CHATLIEU3 & Chọn chất liệu vải nhung, nhựa & 3.75 & 0.861 \\
\hline CHATLIEU4 & Chọn chất liệu hàng mây tre lá & 3.68 & 0.892 \\
\hline CHATLIEU5 & Chọn chất liệu gạch, đá đẹp & 3.87 & 0.886 \\
\hline KIEUDANG1 & Thích chọn kiểu dáng cầu kỳ tỉ mĩ & 3.85 & 0.808 \\
\hline KIEUDANG2 & Thích chọn kiểu dáng Châu Âu, sang trọng & 3.91 & 0.754 \\
\hline KIEUDANG3 & Thích chọn kiểu cổ điển & 3.85 & 0.774 \\
\hline KIEUDANG4 & Thích chọn kiểu hài hòa & 4.65 & 0.817 \\
\hline KIEUDANG5 & Thích chọn kiểu mộc mạc đơn giản & 4.62 & 0.910 \\
\hline MAUSAC1 & Thích chọn màu sắc tươi sang & 4.52 & 1.095 \\
\hline MAUSAC2 & Thích chọn màu tối mạnh mẽ & 3.73 & 0.933 \\
\hline MAUSAC3 & Thích chọn màu cá tính, lạ mắt & 3.85 & 0.835 \\
\hline MAUSAC4 & Thích chọn màu ấm cúng tạo không gian hạnh phúc & 4.37 & 0.694 \\
\hline MAUSAC5 & Thích màu của thiên nhiên thư giãn, yên tỉnh & 4.66 & 0.754 \\
\hline $\mathrm{K} 1$ & $\begin{array}{l}\text { Ngoài bàn, ghế, sofa, phòng khách còn được trang trí } \\
\text { vật khác }\end{array}$ & 4.17 & 0.749 \\
\hline $\mathrm{K} 2$ & Vật trang trí khác cũng có giá trị & 4.03 & 0.701 \\
\hline K3 & Hài lòng về chất lượng mặt hàng TTNT đã mua & 4.75 & 0.668 \\
\hline K4 & Hài lòng về dịch vụ kèm theo khi mua hàng TTNT & 4.69 & 0.751 \\
\hline K5 & Hài lòng về quyết định mua hàng TTNT & 4.78 & 0.626 \\
\hline
\end{tabular}

Nguồn: Kết quả từ phần mềm SPSS 26 của tác giả

Gia đình là nhân tố xã hội, gia đình có ấm no hạnh phúc thì xã hội mới hòa bình và phát triển. Mỗi căn nhà là một tổ ấm của gia đình, nơi mà các thành viên thư giãn, nghỉ ngơi và tái tạo lại sức lao động, làm việc cho xã hội. Tùy theo hoàn cảnh, sở thích và thu nhập, các gia đình 
luôn ý thức chăm chút cho không gian sống của họ sao cho thoải mái nhất. Việc trang trí mặt hàng nội thất cho phòng khách là một trong những quan tâm của các hộ gia đình cho căn nhà của họ. Kết quả nghiên cứu từ khảo sát cho thấy điểm trung bình của các yếu tố khá cao từ 3.67 đến 4.78. Các yếu tố có giá trị trung bình lớn hơn 3 là các yếu tố được khách hàng quan tâm. Giá trị trung bình của yếu tố "Cần trang trí phòng khách cho ngôi nhà thật đẹp" có mức cao nhất trong nhóm các yếu tố cần thiết trang trí phòng khách, với giá trị là 4.78; cho thấy các hộ gia đình rất quan trọng việc trang trí phòng khách, nó như là bộ mặt của ngôi nhà họ đang sống. Kế đến nhóm các yếu tố về giá cả thì các khách hàng của hộ gia đình ở TP. HCM quan tâm đến những hàng hóa có thương hiệu, điểm trung bình của yếu tố "Chọn mặt hàng có thương hiệu tốt" đạt 4.75; hàng nhập khẩu, hàng cao cấp cũng được quan tâm nhưng không nhiều. Về chất liệu của mặt hàng trang trí nội thất rất đa dạng nhưng đa số khách hàng vẫn thích chất liệu bằng gỗ, yếu tố "Gỗ là chất liệu quan tâm nhất" có điểm trung bình cao nhất là 4.62. Sự chọn lựa về kiểu dáng của mặt hàng trang trí nội thất của khách hàng không có sự chênh lệch nhau nhiều, giá trị trung bình của nhóm yếu tố này đạt mức từ 3.85 đến 4.65 trong đó yếu tố "Thích chọn kiều hài hòa" có giá trị trung bình cao nhất là 4.65. Khách hàng vẫn ưu tiên cho sự hài hòa trong không gian sống, căn nhà đẹp thì đồ trang trí nội thất sang trọng, còn căn nhà đơn giản thì đồ nội thất cũng đơn giản tương xứng. Nhóm yếu tố màu sắc cũng là một sự cân nhắc của khách hàng khi mua sắm mặt hàng trang trí nội thất, yếu tố "Thích màu của thiên nhiên thư giãn, yên tĩnh" đạt giá trị trung bình cao nhất là 4.66 cao hơn giá trị trung bình của yếu tố "Thích chọn màu ấm cúng tạo không gian hạnh phúc" là 4.37. Điều đó cho thấy xu hướng tiêu dùng của khách hàng muốn sống trong thiên nhiên, hòa mình vào thiên nhiên yên tĩnh, họ sợ sự ồn ào ô nhiễm của thành phố.

\subsection{Phân tích nhân tố EFA}

Nhóm nhân tố CANTHIET có hệ số Cronbach's Alpha là $0.664>0.6$ đạt yêu cầu, tuy nhiên có nhân tố CANTHIET5 có hệ số Corrected Item - Total Correlation là $0.166<0.3$ nên bị loại. Nhóm nhân tố GIACA sau khi loại biến GIACA2 có hệ số Cronbach's Alpha là $0.711>0.6$ đạt yêu cầu. Nhóm nhân tố CHATLIEU có hệ số Cronbach's Alpha là $0.699>0.6$ đạt yêu cầu, tuy nhiên có nhân tố CHATLIEU5 có hệ số Corrected Item - Total Correlation là $0.275<0.3$ nên bị loại. Nhóm nhân tố KIEUDANG có hệ số Cronbach's Alpha là $0.622>0.6$ đạt yêu cầu, tuy nhiên có nhân tố KIEUDANG1 và KIEUDANG2 có hệ số Corrected Item - Total Correlation nhỏ hơn 0.3 nên bị loại. Nhóm nhân tố MAUSAC có hệ số Cronbach's Alpha là 0.615 > 0.6 đạt yêu cầu, tuy nhiên có nhân tố MAUSAC1 có hệ số Corrected Item - Total Correlation nhỏ hơn 0.3 nên bị loại. Nhóm nhân tố K có hệ số Cronbach's Alpha là $0.649>0.6$ đạt yêu cầu, tuy nhiên có nhân tố K1 có hệ số Corrected Item - Total Correlation nhỏ hơn 0.3 nên bị loại.

Trong 25 biến độc lập sau khi nghiên cứu sơ bộ đã loại ra 06 biến còn 19 biến đưa vào phân tích nhân tố EFA. Bảng phân tích EFA cho thấy có bốn yếu tố được trích tại eigenvalue bằng 1.152; tổng phương sai trích là $62.513 \%>50 \%$ hợp lệ. Biến quan sát MAUSAC3 tiếp tục bị loại vì có trọng số $<0.5$. Chỉ số KMO đạt 0.861 và sig $=0.000$ cho thấy phân tích nhân tố là thích hợp với dữ liệu hiện tại. Phương pháp phân tích nhân tố dựa vào thông số Eigenvalue, chỉ có những nhân tố nào có Eigenvalue lớn hơn 1 mới được giữ lại trong mô hình phân tích và sau khi chuẩn hóa mỗi biến gốc có phương sai là 1 .

Phân tích nhân tố khám phá EFA cho biến độc lập cho thấy có một yếu tố được trích tại eigenvalue bằng 2.189; tổng phương sai trích là $54.717 \%>50 \%$ hợp lệ. Biến quan sát K2 bị loại vì có trọng số $<0.5$. Chỉ số KMO đạt 0.714 và sig $=0.000$ cho thấy phân tích nhân tố là thích hợp với dữ liệu hiện tại. Theo kết quả ma trận xoay lần cuối, các nhân tố được tập hợp tại Bảng 3: 


\section{Bảng 3}

Tổng hợp kết quả kiểm định thang đo

\begin{tabular}{|c|l|l|c|c|}
\hline Số thứ tự & \multicolumn{1}{|c|}{ Nhân tố } & \multicolumn{1}{|c|}{ Các biến quan sát } & $\begin{array}{c}\text { Loại } \\
\text { biến }\end{array}$ & Kết luận \\
\hline 1 & CTNT & CTNT1, CTNT2, CTNT3, CTNT4 & Độc lập & Đạt \\
\hline 2 & GIACA & GC1, GC3, GC4, GC5 & Độc lập & Đạt \\
\hline 3 & CHATLIEU & $\begin{array}{l}\text { CHATLEU1, CHATLIEU2, CHATLIEU3, } \\
\text { CHATLIEU4 }\end{array}$ & Độc lập & Đạt \\
\hline 4 & KIEUDANG & KIEUDANG3, KIEUDANG4, KIEUDANG5 & Độc lập & Đạt \\
\hline 5 & MAUSAC & MAUSAC2, MAUSAC4, MAUSAC5 & Độc lập & Đạt \\
\hline 6 & KHAC & KHAC3, KHAC4, KHAC5 & $\begin{array}{c}\text { Phụ } \\
\text { thuộc }\end{array}$ & Đạt \\
\hline
\end{tabular}

Nguồn: Kết quả từ phần mềm SPSS26 phân tích dữ liệu của tác giả

Mô hình lý thuyết có 06 nhân tố tác động đến quyết định mua mặt hàng trang trí nội thất phòng khách của các hộ gia đình tại địa bàn TP. HCM với 21 biến quan sát được chấp nhận. Việc phân tích hồi quy được thực hiện để xác định mức độ tác động của 05 nhân tố (Sự cần thiết trang trí nội thất phòng khách; Giá cả; Chất liệu mặt hàng nội thất; Kiểu dáng hàng nội thất và màu sắc mặt hàng nội thất) đến quyết định mua mặt hàng trang trí nội thất như thế nào.

\subsection{Phân tích hồi quy tuyến tính đa biến}

Hồi quy đa biến trong SPSS cho thấy các mức độ phụ thuộc của các biến phụ thuộc vào biến độc lập như thế nào. Trước khi tiến hàng kiểm định bằng phân tích hồi quy tuyến tính bội, mối tương quan giữa các biến mô hình được xem xét dựa vào phương pháp phân tích Correlation (hệ số Pearson Correlation) tại Bảng 4. Kết quả cho thấy biến độc lập có tương quan khá cao với biến phụ thuộc, mối tương quan cao nhất là biến CANTHIET với hệ số $\mathrm{r}$ là 0.726 không vượt quá hệ số điều kiện là 0.85 (John \& Benet-Martinez, 2000) và yếu nhất là biến MAUSAC với hệ số là 0.533 . Mặc khác, các biến độc lập cũng tương quan với nhau khá lớn. Điều đó chứng minh giá trị nghiên cứu giữa các khái niệm đã đạt được. Sau khi phân tích Correlation, phép hồi quy bội được sử dụng để phân tích tác động của các biến độc lập lên biến phụ thuộc.

\section{Bảng 4}

Các hệ số tương quan giữa các biến (Correlations)

\begin{tabular}{llc|c|c|c|c|c} 
& & K & CANTHIET & GIÁCẢ & CHATLIEU & KIEUDANG & MAUSAC \\
\hline K & Hệ số tương quan Pearson & 1 & $0.726^{* *}$ & $0.608^{* *}$ & $0.636^{* *}$ & $0.555^{* *}$ & $0.532^{* *}$ \\
\hline & Mức ý nghĩa (2 đuôi) & & 0.000 & 0.000 & 0.000 & 0.000 & 0.000 \\
\hline & Số quan sát & 275 & 275 & 275 & 275 & 275 & 275 \\
\hline \multirow{2}{*}{ CANTHIET } & Hệ số tương quan Pearson & $0.726^{* *}$ & 1 & $0.655^{* *}$ & $0.761^{* *}$ & $0.776^{* *}$ & $0.681^{* *}$ \\
\hline & Mức ý nghĩa (2 đuôi) & 0.000 & & 0.000 & 0.000 & 0.000 & 0.000 \\
\hline \multirow{2}{*}{ GIACA } & Số quan sát & 275 & 275 & 275 & 275 & 275 & 275 \\
\hline & Hệ số tương quan Pearson & $0.608^{* *}$ & $0.655^{* *}$ & 1 & $0.593^{* *}$ & $0.407^{* *}$ & $0.440^{* *}$ \\
\hline & Mức ý nghĩa (2 đuôi) & 0.000 & 0.000 & & 0.000 & 0.000 & 0.000 \\
\hline & Số quan sát & 275 & 275 & 275 & 275 & 275 & 275 \\
\hline
\end{tabular}




\begin{tabular}{ccc|c|c|c|c|c} 
& $\mathbf{K}$ & CANTHIET & GIÁCẢ & CHATLIEU & KIEUDANG & MAUSAC \\
\hline CHATLIEU Hệ số tương quan Pearson & $0.636^{* *}$ & $0.761^{* *}$ & $0.593^{* *}$ & 1 & $0.656^{* *}$ & $0.640^{* *}$ \\
\hline Mức ý nghĩa (2 đuôi) & 0.000 & 0.000 & 0.000 & & 0.000 & 0.000 \\
\hline Số quan sát & 275 & 275 & 275 & 275 & 275 & 275 \\
\hline KIEUDANG & Hệ số tương quan Pearson & $0.555^{* *}$ & $0.776^{* *}$ & $0.407^{* *}$ & $0.656^{* *}$ & 1 & $0.605^{* *}$ \\
\hline & Mức ý nghĩa (2 đuôi) & 0.000 & 0.000 & 0.000 & 0.000 & & 0.000 \\
\hline SẤ quan sát & 275 & 275 & 275 & 275 & 275 & 275 \\
\hline MAUSAC & Hệ số tương quan Pearson & $0.532^{* *}$ & $0.681^{* *}$ & $0.440^{* *}$ & $0.640^{* *}$ & $0.605^{* *}$ & 1 \\
\hline & Mức ý nghĩa (2 đuôi) & 0.000 & 0.000 & 0.000 & 0.000 & 0.000 & \\
\hline & Số quan sát & 275 & 275 & 275 & 275 & 275 & 275 \\
\hline
\end{tabular}

Chú thích: ** Có ý nghĩa với độ tin cậy 99\% (2 đuôi)

Nguồn: Kết quả từ phần mềm SPSS26 phân tích dữ liệu của tác giả

\section{Bảng 5}

Phân tích phương sai

\begin{tabular}{|c|l|c|c|c|c|c|}
\hline $\begin{array}{c}\text { Mồ } \\
\text { hình }\end{array}$ & $\begin{array}{c}\text { Tổng bình } \\
\text { phương }\end{array}$ & Df & $\begin{array}{c}\text { Sai số chuẩn của } \\
\text { ước lượng }\end{array}$ & F & Mức ý nghĩa \\
\hline 1 & Hồi quy & 37.861 & 5 & 7.577 & 70.863 & $0.000^{\mathrm{b}}$ \\
\hline & Sồ dư & 28.744 & 269 & 0.107 & & \\
\hline & Tổng & 66.605 & 274 & & & \\
\hline
\end{tabular}

Chú thích:

a. Biến phụ thuộc: K (HÀ̀ LÒNG)

b. Ước lượng: (Hằng số) CANTHIET, GIACA, CHATLIEU, MAUSAC, KIEUDANG

Nguồn: Kết quả từ phần mềm SPSS26 phân tích dữ liệu của tác giả

Bảng 5 cho thấy Sig kiểm định $=0<0.05$, như vậy, mô hình hồi quy tuyến tính bội phù hợp với tập dữ liệu và có thể sử dụng được.

\section{Bảng 6}

Hệ số tương quan

\begin{tabular}{|c|c|c|c|c|c|c|c|}
\hline \multicolumn{8}{|c|}{ Coefficients $^{\mathbf{a}}$} \\
\hline & \multirow{2}{*}{ Mô hình } & \multicolumn{2}{|c|}{ Hệ số chưa chuẩn hóa } & \multirow{2}{*}{$\frac{\text { Hệ số chuẩn hóa }}{\text { Beta }}$} & \multirow{2}{*}{ Giá trị t } & \multirow{2}{*}{$\begin{array}{l}\text { Mức ý } \\
\text { nghĩa }\end{array}$} & \multirow{2}{*}{ Dung sai } \\
\hline & & $\mathrm{B}$ & Lỗi tiêu chuẩn & & & & \\
\hline \multirow{6}{*}{1} & (Constant) & 1.547 & 0.175 & & 8.834 & 0.000 & \\
\hline & CANTHIET & 0.377 & 0.072 & 0.454 & 5.235 & 0.000 & 0.213 \\
\hline & GIACA & 0.165 & 0.044 & 0.210 & 3.759 & 0.000 & 0.515 \\
\hline & CHATLIEU & 0.104 & 0.049 & 0.140 & 2.115 & 0.035 & 0.366 \\
\hline & KIEUDANG & 0.000 & 0.049 & 0.000 & 0.002 & 0.998 & 0.358 \\
\hline & MAUSAC & 0.36 & 0.050 & 0.041 & 0.721 & 0.472 & 0.492 \\
\hline
\end{tabular}

Chú thích: a. Biến phụ thuộc: K (HÀI LÒNG)

Nguồn: Kết quả từ phần mềm SPSS26 phân tích dữ liệu của tác giả 
Bảng 6 cho thấy mức ý nghĩa kiểm định giá trị t hệ số hồi quy của các biến độc lập có hai biến bị loại là MAUSAC (màu sắc) và KIEUDANG (kiểu dáng) $>0.05$. Hay nói cách khác là hai biến này không có tác động nhiều đến quyết định mua hàng trang trí phòng khách của các khách hàng. Hệ số hồi quy của ba biến (CANTHIET, GIACA, CHATLIEU) nhỏ hơn 0.05 nghĩa là có tác động cùng chiều với biến phụ thuộc. Dựa vào độ lớn của hệ số hồi quy chuẩn hóa Bata, thứ tự tác động từ mạnh nhất tới yếu nhất của các biến độc lập tới biến phụ thuộc là:

$$
\text { CANTHIET (0.454) > GIACA (0.210) > CHATLIEU (0.140) }
$$

Phương trình hồi quy tuyến tính tương ứng với:

$$
\text { HÀI LÒNG }=0.454 * \text { CANTHIET }+0.210 * \text { GIACA }+0.140 * \text { CHATLIEU }
$$

Biến Sụ cần thiết trang trí nội thất tác động mạnh nhất đến quyết định mua và hài lòng về hàng trang trí nội thất đã mua của khách hàng. Trong nhóm yếu tố cần thiết trang trí nội thất phòng khách thì yếu tố "Cần trang trí phòng khách cho ngôi nhà thật đẹp" được lựa chọn nhiều hơn cả, kế đến là yếu tố "đơn giản tiện dụng" và "ấm cúng". Yếu tố "dùng đồ nọi thất thông minh" trong phòng khách chưa được khách hàng chú trọng lắm, có thể vì diện tích phòng khách của các căn hộ ở TP. HCM vẫn còn đủ rộng hoặc vì người dân chưa có thói quen dùng hàng nội thất thông minh.

Biến Giá $\boldsymbol{c a ̉}$ tác động mạnh thứ hai đến quyết định mua và hài lòng về hàng trang trí nội thất đã mua của khách hàng. Trong nhóm yếu tố giá cả hàng trang trí nội thất có hai yếu tố được khách hàng chọn nhiều: (1) Thương hiệu tốt; (2) Hàng nhập khẩu. Biến giá cả "Mặt hàng trung bình" không hợp lệ khi phân tích EFA.

Biến Chất liệu tác động mạnh thứ ba đến quyết định mua và hài lòng về hàng trang trí nội thất đã mua của khách hàng. Trong nhóm yếu tố chất liệu hàng trang trí nội thất có hai yếu tố được khách hàng chọn nhiều: (1) Chất liệu gỗ; (2) Chất liệu vải nhung, nhựa;

Biến Kiểu dáng và Màu sắc không xét đến trong phân tích phương trình hồi quy tuyến tính đa biến vì có hệ số kiểm định $\operatorname{Sig}>0.05$. Điều đó có nghĩa là hai nhóm biến này không ảnh hưởng nhiều đến quyết định mua mặt hàng trang trí nội thất phòng khách của khách hàng như nhóm yếu tố Sụ cần thiết trang trí nội thất, nhóm yếu tố Giá cả và Chất liệu.

\section{Thảo luận kết quả và gọi ý quản lý}

\subsection{Thảo luận kết quả nghiên cứu}

Nghiên cứu này đã kế thừa các lý thuyết nền tảng và kết quả của các nghiên cứu trước để xây dựng mô hình các yếu tố ảnh hưởng đến quyết định mua mặt hàng trang trí nội thất trong phòng khách của người tiêu dùng tại $\mathrm{TP}$. $\mathrm{HCM}$, gồm 06 yếu tố với 30 biến quan sát.

Sau khi tiến hành phân tích hệ số tin cậy Cronbach's Alpha, phân tích nhân tố khám phá EFA, mô hình còn 04 yếu tố với 21 biến quan sát. Kết quả nghiên cứu này cho thấy yếu tố tác động mạnh nhất đến quyết định mua và hài lòng về hàng trang trí nội thất đã mua của khách hàng là yếu tố sự cần thiết trang trí nội thất. Có thể thấy, các chủ hộ ai cũng muốn phòng khách ngôi nhà cần phải trang trí mặt hàng nội thất để tiện lợi trong sinh hoạt gia đình và tiếp khách, không nhất thiết mặt hàng này phải đắt tiền, sang trọng. Tác động kế đến là yếu tố giá cả và yếu tố chất liệu của mặt hàng trang trí nội thất. Yếu tố kiểu dáng và màu sắc mặt hàng nội thất cũng quan trọng nhưng không phải là yếu tố được xem xét khi người tiêu dùng quyết định mua mặt hàng này. Một số gợi ý quản lý được đề xuất như sau: 


\subsection{Gọi ý quản lý}

Thứ nhất, các đơn vị kinh doanh mặt hàng nội thất nên nâng cao sụ̂ thuận tiện mua sắm cho người tiêu dùng. Trước đây, các đơn vị kinh doanh bán sản phẩm tại công ty, cửa hàng hay trung tâm nội thất nay nên chuyển sang tiếp cận thêm và chào bán cho khách hàng với nhiều ưu đãi và thuận tiện qua hình thức online, bán hàng trực tuyến. Theo truyền thống, người dân thích được nhìn ngắm và lựa chọn hàng nội thất trước khi mua, nhưng cũng có nhiều khách hàng chuộng hình thức mua hàng online, trực tuyến. Các đơn vị bán nên tạo một phiên bản trên điện thoại di động cho trang web, đây là cách tối ưu để tiếp cận khách hàng vì đa số khách hàng ngày nay thường dùng điện thoại thông minh để tìm kiếm, lựa chọn và mua sắm và sản phẩm.

Tạo điều kiện thuận tiện nhất cho khách hàng ở cửa hàng, showroom, công ty thực tế hay qua phương thức trực tuyến trên mạng internet để khách hàng có thể tiếp cận xem xét lựa chọn sản phẩm, phương thức thanh toán đơn giản nhanh chóng, thủ tục giao nhận và đổi trả hàng dễ dàng và nhất là quan tâm đến chế độ bảo hành.

Kết quả khảo sát khách hàng đã mua sắm hàng nội thất phòng khách tại các địa điểm cho thấy, có 176 khách hàng (64\%) đã mua sắm hàng nội thất phòng khách tại cửa hàng. 31 khách hàng $(11 \%)$ mua sắm hàng nội thất phòng khách tại công ty; 51 khách hàng $(19 \%)$ mua sắm hàng nội thất phòng khách qua hình thức online; 17 khách hàng $(6 \%)$ mua sắm hàng nội thất phòng khách tại những nơi khác như siêu thị, hội chợ triển lãm, thiết kế riêng...

Thứ hai, về chiến lược sản phẩm. Các cửa hàng, công ty kinh doanh hàng nội thất đã có lựa chọn chủng loại mặt hàng để kinh doanh. Mặt hàng nội thất rất đa dạng chủng loại gồm cả chất liệu, kết cấu, màu sắc, hình dáng; tuy nhiên gỗ vẫn là chất liệu được ưa chuộng của khách hàng (TP. HCM), hình dáng thì đa số khách hàng chuộng kiểu hài hòa mộc mạc đơn giản với màu sắc nghiêng về màu của thiên nhiên thư giãn (màu của gố, màu xanh lá cây, màu thiên nhiên). Những mặt hàng nội thất có kiểu dáng kết cấu cầu kỳ và tỉ mỉ chỉ được quan tâm bởi số ít khách hàng, đây là phân khúc khách hàng có thu nhập cao. Khách hàng ngày nay có xu hướng đặt làm những bộ nội thất theo thiết kế riêng của họ để phù hợp với không gian căn nhà. Vì vậy các đơn vị kinh doanh nội thất nên có đội ngũ tư vấn thiết kế giỏi và chuyên môn để thiết kế ra những sản phẩm có tính thẩm mỹ.

Thứ ba, chú ý về dịch vụ kèm theo khi bán sản phẩm và bán sản phẩm có khuyến mãi. Khi khách hàng mua mặt hàng trang trí nội thất, họ quan tâm đến giá cả và dịch vụ kèm theo của đơn vị bán sản phẩm, đó là dịch vụ vận chuyển, lắp ráp, bảo hành, bảo trì, đổi hàng và nếu sản phẩm có khuyến mãi những vật dụng khác khi mua thì sẽ làm khách hàng hài lòng hơn.

Kết quả khảo sát cho thấy, mức độ hài lòng về dịch vụ kèm theo khi mua mặt hàng trang trí nội thất có thang điểm từ 1-5, trong đó có 192 người (chiếm 70\%) đã hài lòng với điểm số 4 và 5 .

\subsection{Hạn chế và hướng nghiên cứu tiếp theo}

Nghiên cứu này có mục tiêu chính là khám phá các yếu tố có tác động đến quyết định mua mặt hàng trang trí nội thất của khách hàng (các hộ gia đình) tại TP. HCM từ đó giúp cho các đơn vị kinh doanh hàng nội thất nắm bắt được nhu cầu và xu hướng mua sắm mặt hàng trang trí nội thất của người dân nói chung và các hộ gia đình nói riêng. Tuy nhiên nghiên cứu này còn tồn tại một số hạn chế như:

Thứ nhất, nghiên cứu này chỉ được thực hiện ở TP. HCM với số lượng mẫu tương đối thấp (275 mẫu chính thức) do đó tính tồng quát và đại diện chưa cao. Thứ hai, nghiên cứu chỉ mới thực hiện được cho mặt hàng nội thất phòng khách, còn chưa nghiên cứu cho nội thất nhà 
bếp, phòng ngủ và tính phong thủy trong trang trí nội thất. Thứ ba, nghiên cứu chưa phân loại trang trí nội thất cho căn hộ chung cư và nhà phố, nhà biệt thự. Thứ tư, các nhóm yếu tố ảnh hưởng vẫn còn hạn chế chưa bao quát hết về quyết định mua mặt hàng trang trí nội thất của khách hàng.

Những vấn đề này sẽ định hướng cho những nghiên cứu tiếp theo.

\section{Tài liệu tham khảo}

Do, H. T. H. (2017). Nghiên cưu các yếu tố tác động đến quyết định mua ô tô tại Việt Nam [Research on factors affecting the decision to buy a car in Vietnam] (Master's thesis). University of Economics Ho Chi Minh City, Ho Chi Minh City, Vietnam.

Fishbein, M., \& Ajzen, I. (1975), Belief attitude, intention and behavior: An introduction to the theory and research. Boston, MA: Addison-Wesley.

Hair, J. F., Black, W. C., Babin, B. J., \& Anderson, R. E. (2014). Multivariate data analysis (7th ed.). London, UK: Pearson Education Limited.

Hoang, T., \& Chu, N. N. M. (2008). Phân tích dĩ liệu nghiên cúu với SPSS [Analyze research data with SPSS]. Ho Chi Minh, Vietnam: NXB Hồng Đức.

Huynh, T. T. Q. (2013). Các yếu tố ảnh hương đến quyết định mua xe tay ga hãng Honda của người tiêu dùng tại Thành phố Hồ Chí Minh [Factors affecting consumers' decision to buy Honda scooters in Ho Chi Minh City] (Master's thesis). University of Economics Ho Chi Minh City, Ho Chi Minh City, Vietnam.

Jeff, B. (n.d.) Consumer behaviour theory: Approaches and models. Retrieved May 20, 2020, from http://eprints.bournemouth.ac.uk/10107/1/Consumer_Behaviour_Theory__Approaches_\%26_Models.pdf

John, O. P., \& Benet-Martinez, V. (2000). Measurement: Reliabitily, construct vilidation, and scale construction. In H. T. Reis \& C. M. Judd (Eds.), Handbook of research methods in social psychology (pp. 39-369). New York, NY: Cambridge University Press.

Kotler, P., \& Kelle, K. L. (2012). Marketing management. Upper Saddle River, NJ: Prentice Hall

Le, P. (2020). TP. HCM uu tiên phát triển nhà ở [Ho Chi Minh City prioritizes housing development]. Retrieved May 25, 2020, from Cafef website: https://cafef.vn/tp-hcm-uutien-phat-trien-nha-o-20200702093802185.chn

Nguyen, T. D. (2013). Phưong pháp nghiên cúu khoa học trong kinh doanh [Scientific research methods in business]. Hanoi, Vietnam: NXB Lao động - Xã hội.

Nguyen, T. Q. (2014). Một số yếu tố tác động đến quyết định chọn mua căn hộ chung cư cao cấp của khách hàng tại Thành phố Hồ Chí Minh [Some factors affecting customers' decision to buy luxury apartments in Ho Chi Minh City]. Tạp chí Phát triển Kinh tế, 279.

Nguyen, V. V. (2016). Các yếu tố giá trị thuơng hiệu ảnh hưởng đến ý định chọn mua nệm Kim dan cuia NTD TP. HCM [Brand value factors affect the intention to buy needle knit mattress of NTD TP. HCM] (Master's thesis). University of Finance-Marketing, Ho Chi Minh City, Vietnam.

Nhat Minh (2020). TPHCM - Trung tâm kinh tế, không ngùng đột phá, sáng tạo, phát triển [Ho Chi Minh City - Economic center, constantly breaking through, creating and developing]. 
Retrieved May 25, 2020, from Đảng bộ Thành phố Hồ Chí Minh website: https://www.hcmcpv.org.vn/tin-tuc/tphcm-trung-tam-kinh-te-khong-ngung-dot-pha-sangtao-phat-trien-1491864607

Pham, P. T. H. (2009). Nghiên cưu các yếu tố ảnh hwởng đến quyết định mua vật liệu nhẹ- Thạch cao [Research on factors affecting the decision to buy lightweight materials - Gypsum] (Master's thesis). Ho Chi Minh City Open University, Ho Chi Minh City, Vietnam.

Kaplan, R. S., \& Norton, D. P. (1996). The balanced scorecard. Boston, MA: Havard Business School Press.

Solomon, M., Bamossy, G., Akegaard, S., \& Hogg, M. K. (2006). Cosumer behavior: A european perspective (3rd ed.). London, UK: Person Education Lomited.

Thu Hang (2018). TP. HCM có múc lương trung bình cao nhất toàn quốc [Ho Chi Minh City has the highest average salary in the country]. Retrieved May 26, 2020, from Thanh niên website: https://thanhnien.vn/tai-chinh-kinh-doanh/tphcm-co-muc-luong-trung-binh-caonhat-toan-quoc-938809.html

Vo, N. P. T. (2013). Các yếu tố ảnh hưởng đến quyết định mua nhà của khách hàng tại TP.HCM [Factors affecting customers' decision to buy a house in Ho Chi Minh City] (Master's thesis). University of Economics Ho Chi Minh City, Ho Chi Minh City, Vietnam. 